\title{
Six years' experience with perthoracic core needle biopsy in pulmonary lesions
}

\author{
A MORGENROTH, H P PFEUFFER, M AUSTGEN, HJ VIERECK, \\ F TRENDELENBURG
}

From the Klinik Michelsberg, Münnerstadt, and the Division of Pneumonology, University of Saarland, Homburg, Federal German Republic

\begin{abstract}
Six years' experience of percutaneous core needle biopsy using the Hausser needle in 502 patients, aged 20-89 years, is reported. A biopsy was carried out when sputum and bronchoscopic methods had failed to establish a definitive histological diagnosis. Over $60 \%$ of the lesions were peripheral and about $40 \%$ were $2-4 \mathrm{~cm}$ in diameter. A correct diagnosis was made by this means in 312 of the 339 patients shown eventually to have a malignant lesion (92\%) and in 130 of 146 patients with a benign lesion (89\%). A definitive diagnosis was never established in 17 patients. Complications arose in $15 \%$ of cases. Pneumothorax occurred in 43 patients (7\%), of whom 12 required a chest drain. Further complications included a small haemoptysis $(<30 \mathrm{ml})$ in 27 patients $(5 \%)$, haemothorax necessitating a chest drain in three patients, and an intrapulmonary haematoma in five patients. There were no fatal or permanent complications. Percutaneous core needle biopsy is a valuable procedure with a high diagnostic accuracy in these patients and a low rate of complications.
\end{abstract}

\section{Introduction}

Percutaneous needle biopsy is a well established procedure for obtaining a diagnosis from tissue from pulmonary lesions, when sputum and bronchoscopic methods have failed..$^{1-12}$ In most cases the biopsy provides a diagnosis and avoids the need for a diagnostic thoracotomy. ${ }^{51013-16}$ The two main methods used are aspiration biopsy and core or cutting needle biopsy, the advantage of the latter method being that it provides tissue for histological assessment. We used a 14 gauge needle, as it is easier to handle than a fine needle and diagnostic material may be obtained more often with core needles.

This article summarises six years' experience with percutaneous core needle biopsy using the Hausser needle $^{17}$ in the diagnosis of localised pulmonary lesions.

Address for reprint requests: Dr A Morgenroth, Klinik Michelsberg, D-8732 Münnerstadt, Federal German Republic.

Accepted 22 December 1988

\section{Methods}

\section{PATIENTS}

During the six years 502 patients, 153 female and 349 male, underwent percutaneous lung biopsy. There was a wide age range, from 20 to 89 years, though $60 \%$ of the group were aged 40-59 years (table 1). Most chest radiographs showed a solitary lesion. In the small number of patients with multiple lesions, we tried to biopsy the most peripheral lesion.

Percutaneous core needle biopsy was carried out when other methods, such as sputum culture and sputum cytology, bronchoscopy with bronchial brushings, and bronchial or transbronchial biopsy, had failed to establish a definitive histological diagnosis. Contraindications to biopsy included emphysematous blebs or bullae; poor respiratory functions $\left(\mathrm{FEV}_{1}<1\right.$ 1), recent severe haemoptysis, a bleeding

Table 1 Age distribution of the patients studied

\begin{tabular}{lrllllllll}
\hline Age $(y):$ & $20-29$ & $30-39$ & $40-49$ & $50-59$ & $60-69$ & $70-79$ & $80-89$ & Total \\
\hline Female & 5 & 16 & 39 & 61 & 22 & 9 & 1 & 153 \\
Male & 13 & 48 & 83 & 117 & 65 & 17 & 6 & 349 \\
\hline
\end{tabular}


diathesis, vascular malformations, pulmonary hypertension, a suspected Echinococcus cyst, contralateral pneumonectomy, and non-cooperation.

\section{BIOPSY}

The risk of complications, pulmonary function, and arterial blood gas tensions were assessed before biopsy and the prothrombin time and platelet count were determined one hour before the biopsy was carried out. Posteroanterior and lateral chest radiographs were used to locate the lesion.

The Hausser needle (Unimed SA, Lausanne, Switzerland) consists of an outer stainless steel cannula (2.1 mm diameter, $105 \mathrm{~mm}$ long) containing an exchangeable trocar and a split cutting needle (length $12 \mathrm{~cm}, 14$ gauge) (fig 1 ).

Patients were premedicated with $7.5 \mathrm{mg}$ hydrocodone bitartrate subcutaneously half an hour before the procedure. After fluoroscopic localisation of the lesion the skin was cleaned and the skin, underlying tissue, and parietal pleura were anaesthetised with $2 \%$ lignocaine. A small skin incision was made and the biopsy needle inserted under biplanar

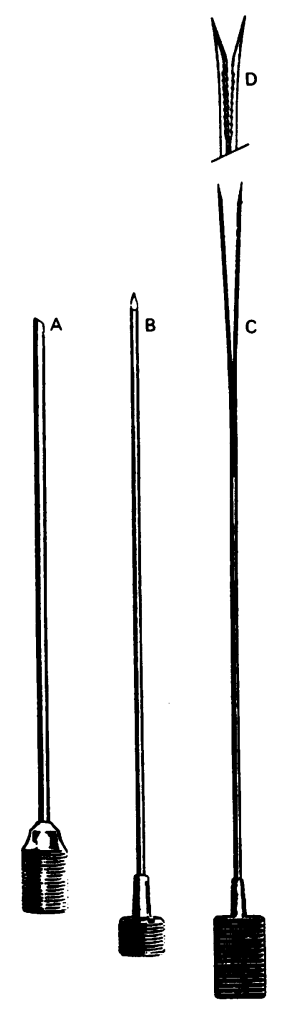

Fig 1 Hausser-needle: $A$-cannula; $B$-trocar; $C$-cutting needle; $D$-distal part of the cutting needle. fluoroscopic control. Breath holding was limited to the time when the needle was crossing the pleura; the $\overrightarrow{\vec{F}}$ patient was instructed to breathe shallowly at other times. After confirmation that the tip of the instrument? was positioned in the middle of the lesion the trocar $\frac{\bar{D}}{\bar{D}}$ was replaced with the needle. The blades of the needle $\overrightarrow{\widetilde{\sigma}}$ opened when it was pushed forward, and the outero sheath with its distal cutting edge was inserted over the needle and compressed the blades. The needle was $\vec{\circ}$ then removed with the specimen, about $10-20 \mathrm{~mm}$ in length, trapped between the blades.

In the case of large lesions samples were also taken from the periphery of the lesion. Specimens were fixed $\vec{x}$ in formalin. If it was suspected that the lesion was infected part of the specimen was sent for culture. A $\omega$ posteroanterior chest radiograph was taken at end $\vec{y}$ expiration immediately after the biopsy and on the following day (or sooner if symptoms suggested a $a^{\circ}$ pneumothorax or other complications). Pulse rate and $\bar{z}_{\bar{\gamma}}^{-}$ blood pressure were monitored for 24 hours after biopsy.

\section{Results}

The 502 patients underwent 586 consecutive percu-o taneous core needle biopsies. The lesion proved to be malignant in 339 patients and benign in 146;17\% patients were lost to follow up and the final diagnosis is unknown (table 2).

\section{DIAGNOSES}

Of the 339 malignant lesions, 312 were diagnosed by core needle biopsy (92\%); most diagnoses were con firmed by surgery. In 27 patients core needle biopsy did not establish the diagnosis, or the specimen waș interpreted as being "suggestive of malignancy." The diagnosis of malignancy in these 27 patients was made 3 at surgery in 14, by follow up in eight, and at necropsyo in five. The diagnostic yield per biopsy was $79 \%$; more than one attempt at biopsy was made in some patients. The histological diagnosis was of primary bronchiaP carcinoma in 302 and metastasis from extrathoracie
carcinoma in 37 patients $(11 \%)$.

Of the 146 lesions that were eventually shown to bes benign, a definitive diagnosis was established by corê needle biopsy in 130 patients $(89 \%)$. In all cases follow up of more than one year has confirmed the benign nature of the diagnosis. There were 43 non-specifie granulomatous lesions and six hamartomas; 2 은 patients had a core of fibrosis, 23 organising pneumonia, and 21 non-specific inflammation: Mycobacterium tuberculosis was identified in $13^{\circ}$ patients, Aspergillus sp in one and Histoplasma sp in two. Core needle biopsy gave a false positive diagnosis of malignancy in five patients and failed to establish the nature of the diagnosis in 11 . In these 11 patient 
Table 2 Diagnostic results

\begin{tabular}{|c|c|c|c|c|c|c|}
\hline & \multirow{2}{*}{$\begin{array}{l}\text { No of } \\
\text { patients }\end{array}$} & \multirow{2}{*}{$\begin{array}{l}\text { No of } \\
\text { punctures }\end{array}$} & \multirow{2}{*}{$\begin{array}{l}\text { Number } \\
\text { correct }\end{array}$} & \multirow{2}{*}{$\begin{array}{l}\text { Number } \\
\text { inconclusive }\end{array}$} & \multicolumn{2}{|l|}{ Accuracy } \\
\hline & & & & & $\%$ patients & $\%$ punctures \\
\hline Total & 502 & 586 & 442 & 60 & 88 & 75 \\
\hline $\begin{array}{l}\text { No diagnosis } \\
\text { Benign diseases } \\
\text { Malignant diseases }\end{array}$ & $\begin{array}{r}17 \\
146 \\
339\end{array}$ & $\begin{array}{r}17 \\
173 \\
396\end{array}$ & $\begin{array}{l}\overline{130} \\
312\end{array}$ & $\begin{array}{l}17 \\
16+ \\
27\end{array}$ & $\begin{array}{l}\overline{89} \\
92\end{array}$ & $\begin{array}{l}\overline{75} \\
79\end{array}$ \\
\hline $\begin{array}{l}\text { Primary bronchial carcinoma } \\
\text { Squamous cell carcinoma } \\
\text { Primary adenocarcinoma } \\
\text { Large cell undifferentiated carcinoma } \\
\text { Small cell anaplastic carcinoma } \\
\text { Other bronchial carcinoma } \\
\text { Metastasis of extrathoracic carcinoma }\end{array}$ & $\begin{array}{r}302 \\
123 \\
63 \\
61 \\
41 \\
14 \\
37\end{array}$ & $\begin{array}{r}342 \\
134 \\
67 \\
66 \\
52 \\
23 \\
54\end{array}$ & $\begin{array}{r}283 \\
119 \\
61 \\
58 \\
34 \\
11 \\
29\end{array}$ & $\begin{array}{r}19 \\
4 \\
2 \\
3 \\
7 \\
3 \\
8\end{array}$ & $\begin{array}{l}94 \\
97 \\
97 \\
95 \\
83 \\
79 \\
78\end{array}$ & $\begin{array}{l}83 \\
89 \\
91 \\
88 \\
65 \\
48 \\
54\end{array}$ \\
\hline
\end{tabular}

* One malignant schwannoma; one pulmonary oncocytoma; three carcinoid; three cylindroma; six alveolar cell carcinoma.

†Including five cases false positive for carcinoma.

and the 21 with "non-specific inflammation" in the biopsy specimen the lack of malignant cells was accepted as evidence that the lesion was benign because the following criteria were fulfilled: the lesion was visible in two projections, the needle was seen to go into the lesion several times, adequate material was obtained, and histological examination showed abnormal lung tissue.

The lesions disappeared within one year in all patients with non-specific inflammation and in three of the 11 patients in whom biopsy did not establish the nature of the benign lesions. The lesions remained unchanged in the other eight patients. A false positive diagnosis of cancer was made in five patients, in all instances from a repeat biopsy after a non-diagnostic first biopsy. Three patients were believed to have lymphoma but organising pneumonia was found at surgery in two and focal chronic pneumonia in the third. In the fourth patient a tuberculosis granuloma was resected after biopsy had suggested metastatic breast cancer and in the fifth patient the lesion proved to be a hamartoma.

Of the 502 patients in the study, 44 had a second biopsy because the first biopsy was inconclusive and 40 had a third biopsy. In 38 of the 84 cases repeat biopsy also failed to establish a definitive diagnosis; these included 14 patients with lesions less than $2 \mathrm{~cm}$ in diameter. The proportions of patients with a successful biopsy is shown according to the size of the lesion on the chest radiograph in figure 2 and according to the depth of the lesion from the biopsy site in figure 3 . We failed to obtain diagnostic material from $14(42 \%)$ lesions less than $2 \mathrm{~cm}$ in diameter. The lesion lay less than $4 \mathrm{~cm}$ from the body surface in 105 cases $(21 \%)$ and at a depth of $8 \mathrm{~cm}$ or more in 75 patients $(15 \%)$. In seven of these 75 patients a diagnosis could not be established.

\section{COMPLICATIONS}

The complication rate overall was $15 \%$ (table 3 ).
Pneumothorax occurred in 43 patients $(7 \%)$, requiring an intercostal tube in $12(2 \%)$. In the remainder the pneumothorax was asymptomatic and required observation only. Haemoptysis occurred after 27 procedures $(5 \%)$, but no more than $20-30 \mathrm{ml}$ of blood was expectorated on any occasion and no treatment was required.

Three patients developed a haemothorax of several hundred millilitres that required chest tube drainage, and five patients developed an intrapulmonary haematoma. Transient dizziness and hypotension occurred in nine patients. Lesions deeper than $7 \mathrm{~cm}$ were associated with more haemorrhagic complications. There were no cases of air embolism and no deaths attributable to the procedure. No dissemination of tumour cells in the biopsy track or pleural space was observed during the hospital stay, at outpatient observation, or at necropsy.

\section{Discussion}

Sputum examination and bronchoscopic investigation provides a diagnosis in most patients with solitary or multiple pulmonary lesions on the chest radiograph but an appreciable proportion of patients remain undiagnosed after undergoing these procedures. Percutaneous needle biopsy and diagnostic thoracotomy are alternative methods of establishing a diagnosis. Diagnostic thoracotomy will provide

Table 3 Complications in the 586 procedures

\begin{tabular}{lll}
\hline & $n$ & $\%$ \\
\hline No complications & 499 & 85 \\
Pneumothorax & 31 & 5 \\
$\quad$ not requiring chest drain & 12 & 2 \\
$\quad$ requiring chest drain & 27 & 5 \\
Haemoptysis & 3 & 1 \\
Haemothorax & 5 & 1 \\
Shtrapulmonary haematoma & 9 & 2 \\
\hline
\end{tabular}




\section{No of}

patients

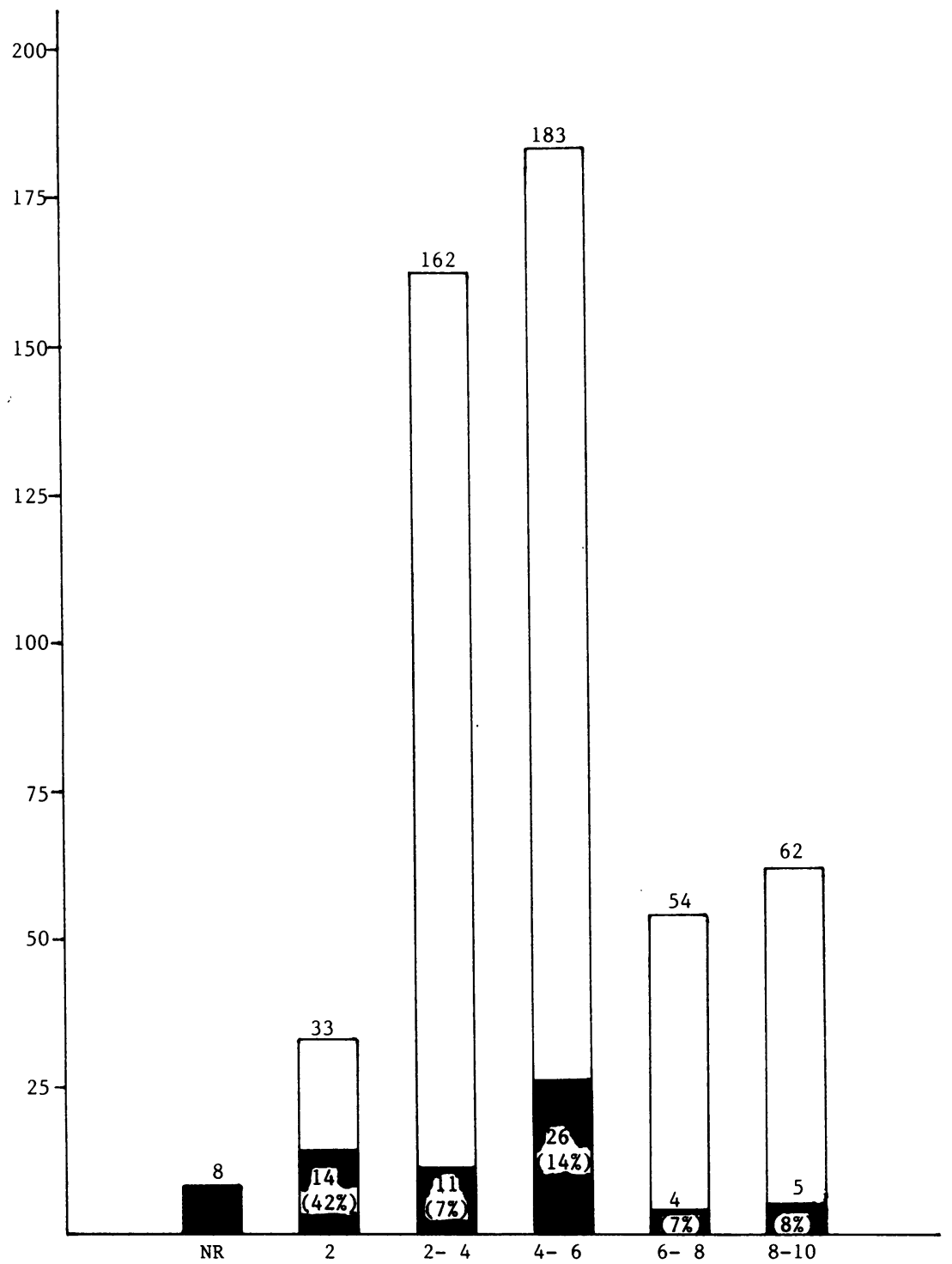

Fig 2 Distribution of the size of the lesions on the chest radiographs of the 502 patients.

Inconclusive biopsies $N R$-not recorded.

Size $(\mathrm{cm})$

sufficient material for a definitive diagnosis and for some patients with malignant lesions has the advantage that an attempt at curative resection may be made at the same time. Most lesions, however, in older patients in particular, may be expected to be malignant and most will be non-resectable at the time of presentation. $^{18}$ Moreover, in some cases benign lesions that do not require surgical treatment will be found or malignant lesions for which chemotherapy is $\stackrel{\circ}{\circ}$ preferred. In view of this and the considerable morbidity associated with thoracotomy, it seems reasonable to try initially to establish a diagnosis by percutaneous needle biopsy. The two main methods $\underset{\mathbb{D}}{\stackrel{D}{ }}$ used are aspiration and core or cutting needle biopsy. $\frac{\rho}{\square}$ Aspiration biopsy has been shown to be safe and effec- $\triangle$ tive, ${ }^{5-7,131419-22}$ though we believe, especially when 
No of

patients

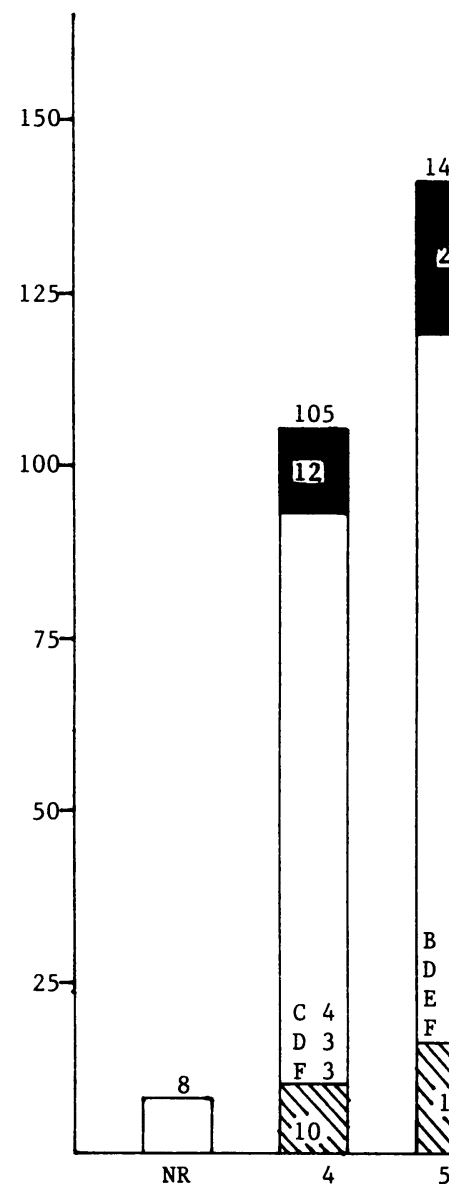

Fig 3 Distribution of the depth of the lesions from the skin surface of the 502 patients.

Inconclusive biopsies

Complications

$N R$ - not recorded

A-intrapulmonary haematoma

$B$-haemothorax

C-haemoptysis

D-pneumothorax without chest tube

$E$-pneumothorax requiring chest tube

$F$-short term dizziness or hypotension.

malignancy is present, that the value of aspiration biopsy is limited because the specimen is very small and the lack of definite cell arrangement in smears often prevents accurate identification and grading of the lesion. ${ }^{1314} 19-22$ In larger lesions necrotic material only may be obtained, making cytological diagnosis impossible. ${ }^{19} 21-23$ In addition, not all pathologists have the experience to make a definitive diagnosis from cytological material. ${ }^{212324}$ A core needle biopsy provides material for histological examination and should lead to correct identification of the nature of the lesion, thus facilitating the planning of appropriate and efficient treatment. In our study 312 of 339 cases of malignancy were confirmed by percutaneous core needle biopsy, a diagnostic yield of $92 \%$ and a yield per puncture of $79 \%$. In 27 patients where percutan- eous core needle biopsy failed to provide a diagnosis malignancy was eventually confirmed by surgery, follow up, or necropsy. The accuracy with which the diagnosis of malignancy was established in our study is in accordance with that in other studies. ${ }^{13} 1625-29$

The diagnostic yield varied with the type of tumour, being low in cases of carcinoid, malignant schwannoma, pulmonary oncocytoma, cylindroma, alveolar cell carcinoma, and metastastic carcinoma, but $80 \%$ or more in cases of undifferentiated large cell carcinoma, squamous cell carcinoma, and primary adenocarcinoma. In the 41 patients with small cell anaplastic carcinoma the yield was only $65 \%$.

Of the 146 patients with benign disease, the diagnosis was established in 130 by core needle biopsy; follow up in all cases confirmed the benign nature of 
the lesions. In the 11 patients in whom no lesion was diagnosed by core needle biopsy follow up for two years or more confirmed the benign nature of the lesion. In the five patients with a false positive diagnosis of malignancy surgery showed organised pneumonia, focal chronic pneumonia, tuberculous granuloma, and hamartoma. The diagnostic yield from the core needle biopsy in patients with a benign lesion was $89 \%$ for patients and $75 \%$ for punctures. These rates are higher than those reported for aspiration cytology. ${ }^{15202230-33}$

Fears of a high complication rate for cutting biopsy needles have been expressed. ${ }^{34}{ }^{35}$ Most of the serious complications, particularly haemorrhage, occur in patients with diffuse or fibrotic lung disease, as emphasised by Zavala and Bedell ${ }^{36}$ and more recently by McEvoy et al ${ }^{13}$ and Balslov et al. ${ }^{37}$ The $15 \%$ complication rate in our study compares well with studies in which aspiration biopsy has been used. The complication rate for cutting needles has varied from $10 \%$ to $60 \%$. $242531353638-4044$

Pneumothorax was the most common complication in our study, occurring in 43 biopsies (7\%); in previous studies the incidence was $24-57 \% .^{782741-43}$ Most of the pneumothoraces were small and merely required observation, though chest tube drainage was necessary in 12 cases. The reason for the small number of pneumothoraces in our study may be that most of the lesions we biopsied were peripheral, and that large lesions as a result of their size are closer to the chest wall. The incidence of pneumothoraces was not, however, influenced by the size of the lesion, or by having more than one attempt at biopsy. ${ }^{43456}$

Haemoptysis of no more than 20-30 ml occurred in 27 patients and required no treatment. Haemothorax of several hundred millilitres occurred in three patients and an intrapulmonary haematoma in five. Haemorrhagic complications occurred more commonly in deep lesions (in $25 \%$ and $28 \%$ of lesions 8 and $9 \mathrm{~cm}$ deep), though the more serious haemorrhagic complications occurred with lesions $5-8 \mathrm{~cm}$ in depth. The low complication rate may be attributed to care in excluding patients with contraindications and to treatment of partial contraindications such as chronic obstructive lung disease or bleeding diathesis before the procedure. Experience and skill are also important.

We conclude that when sputum and bronchoscopic methods, including transbronchial biopsy, have failed to provide a diagnosis perthoracic core needle biopsy using the Hausser-needle is a safe procedure with high diagnostic accuracy, especially in the investigation of localised mid and peripheral pulmonary lesions greater than $2 \mathrm{~cm}$ in diameter. It is particularly valuable for patients unsuitable for invasive procedures as complications are few and usually minor.
We gratefully acknowledge the secretarial assistance: of Mrs Elvira Fleck.

\section{References}

1 Allison DJ, Hemingway AP. Percutaneous needle biops of the lung. Ann Radiol 1982;7:486-8.

2 Chance AB, Dowling EA, Gardner WA. Fine needle aspiration-a six year experience at the University of South Alabama Medical Center. J Med Ass State AlP 1981;51:22-4.

3 Costrini AM. Transthoracic needle aspiration biopsy of focal pulmonary lesions: a community hospital

4 Curcio CG, Rinaldi M, Torachella R, Donnorso RP+ Role of percutaneous fine needle aspiration in the diagnosis of lung cancer: our experience with $14 Q^{-}$ patients. Oncology 1983;40:177-80.

5 Gibney RTN, Man GCW, King EG, LeRiche J. Aspira응 tion biopsy in the diagnosis of pulmonary disease Chest 1981;80:300-3.

6 Herman PG, Hessel SJ. The diagnostic accuracy and complications of closed lung biopsies. Radiolog s 1977;125:11-4.

7 Lalli AF, McCormack LJ, Zelch M, Reich NE, Belovichő D. Aspiration biopsies of chest lesions. Radiology 1978;127:35-40.

8 Malberger E, Lemberg S. Transthoracic fine needlę aspiration cytology. A study of 301 aspirations from 221 cases. Acta Cytol 1982;26:172-8.

9 Pilotti S, Rilke F, Gribaudi G, Damascelli B. Fine needle aspiration biopsy cytology of primary and metastatie pulmonary tumors. Acta Cytol 1982;26:661-6.

10 Rocke DA. Percutaneous lung biopsy. Management of tracheobroncial haemorrhage. Anaesthesia 1984;39: 888-90.

11 Sargent EN, Turner AF, Gordonson J, Schwinn CP Pashky O. Percutaneous pulmonary needle biopsy. report of 350 patients. $A J R$ 1974;122:758-68.

12 Westcott JL. Direct percutaneous needle aspiration of localized pulmonary lesions: results in 422 patients Radiology 1980;137:31-5.

13 McEvoy RD, Begely MD, Antic R. Percutaneous biopsy of intrapulmonary mass lesions. Experience with a disposable cutting needle. Cancer 1983;51:2321-6.

14 Moinuddin SM, Lee LH, Montgomery JH. Mediastina needle biopsy. AJR 1984;143:531-2.

15 Stevens GM, Jackman RJ. Outpatient needle biopsy of the lung: its safety and utility. Radiology 1984;1510 301-4.

16 Flower CDR, Verney GI. Percutaneous needle biopsy of thoracic lesions: an evaluation of 300 biopsies. Clin Radiol 1970;30:215-8.

17 Haußer R. Uber die diagnostische gezielte Gewebspunko tion bei unklaren Lungen-, Pleura- und Mediastinal prozessen. Dtsch Med Wochenschr 1965;41:1809-19. \&

18 Mountain CF. Surgical therapy in lung cancer: biologic, 0 physiologic and technical determinants. Semin Onco $\bar{b}$ 1974;1:253-8.

19 Hajdu SI, Melamed MR. Limitations of aspiration cytology in the diagnosis of primary neoplasms. Acto Cytol 1984:28:337-45. 
20 Konietzko N. Der solitäre Rundherd der Lunge. Int Welt 1984;1:24-7.

21 Leonhardt P, Gosse H, Ballin A. Ergebnisse der transthorakalen Feinnadelbiopsie. Z Erkrank Atm-Org 1982;159:95-102.

22 Strobel SL, Keyhani-Rofagha S, O'Toole RV, Nahman BJ. Nonaspiration-needle smear preparations of pulmonary lesions. A comparison of cytology and histology. Acta Cytol 1985;29:1047-52.

23 Khouri NF, Stitik FP, Erozan YS, et al. Transthoracic needle aspiration biopsy of benign and malignant lung lesions. AJR 1985;144:281-8.

24 Samuelsson L, Albrechtsson U, Tylen U. Fine-needle biopsy of chest lesions. Radiologe 1982;22:493-6.

25 Harrison BDW, Thorpe RS, Kitchener PG, McCann BG, Pilling JR. Percutaneous Trucut lung biopsy in the diagnosis of localised pulmonary lesions. Thorax 1984;39:493-9.

26 Nordenström B, Sinner WN. Needle biopsies of pulmonary lesions. Fortschr Röntgenstr 1978;129: 414-8.

27 Poe RH, Tobin RE. Sensitivity and specificity of needle biopsy in lung malignancy. Am Rev Respir Dis 1980; 122:725-9.

28 Sinner WN. Transthoracic needle biopsy of small peripheral malignant lung lesions. Invest Radiol 1973; 8:305-14.

29 Zelch JV, Lalli AF, McCormack LJ, Belovich DM. Aspiration biopsy in diagnosis of pulmonary nodule. Chest 1973;63:149-52.

30 Caya JG, Clowry LJ, Wollenberg NJ, Tieu TM. Transthoracic fine-needle aspiration cytology. Am J Clin Pathol 1984;82:100-3.

31 Davies DP. Percutaneous lung biopsy in the investigation of intrathoracic lesions. Radiography 1985;598:179-85.

32 Ebner F, Schreyer H, Justich E, Weirer O, Fladerer H. Perkutane transthorakale Feinnadelbiopsie der Lunge. Indikation, Ergebnisse und Komplikationen bei 578 Punktionen Röntgenbl-Bl 1983;36:171-7.

33 Sinner WN. Wert und Bedeutung der perkutanen trans- thorakalen Nadelbiopsie für die Diagnose intrathorakaler Krankheitsprozesse. Fortschr Röntgenstr 1975;123:197-202.

34 Forrest JV, Sagel SS. Cutting needle biopsies [letter]. Chest 1976;69:244-5.

35 Norenberg R, Claxton CP, Takaro T. Percutaneous needle biopsy of the lung: report of two fatal complications. Chest 1974;66:216-8.

36 Zavala DC, Beddell GN. Percutaneous lung biopsy with a cutting needle. Am Rev Respir Dis 1972;106:186-93.

37 Balsløv S, Vestbo J, Viskum K. Value of Tru-cut lung biopsy in focal and diffuse lung disease. Thorax 1988;43:147-50.

38 Deininger HR, Schmidt C. Die Stanzbiopsie der Lunge. Fortschr Röntgenstr 1986;144:656-61.

39 Mehnert JH, Brown MJ. Percutaneous core needle biopsy of peripheral pulmonary masses. Am J Surg 1978;138:151-6.

40 Poe RH, Kallay MC, Wicks CM, Odorofl CL. Predicting risk of pneumothorax in needle biopsy of the lung. Chest 1984;85:232-5.

41 Berquist TH, Bailey PB, Cortese DA, Miller WE. Transthoracic needle biopsy: accuracy and complications in relation to location and type of lesion. Mayo Clin Proc 1980;55:475-81.

42 Fontana RS, Miller WE, Beabout JW, Payne WS, Harrison EG. Transthoracic needle aspiration of discrete pulmonary lesions; experience in 100 cases. Med Clin North Am 1970;54:961-71.

43 House AJS, Thompson KR. Evaluation of new transthoracic needle for biopsy of benign and malignant lung lesions. AJR 1977;129:215-20.

44 Cormier Y, Laviolette M, Tardif A. Prevention of pneumothorax in needle lung biopsy by breathing 100 percent oxygen. Thorax 1980;35:37-41.

45 Crosby JH, Hager B, Høeg K. Transthoracic fine-needle aspiration. Cancer 1985;56:2504-7.

46 Sinner WN. Complications of percutaneous transthoracic needle aspiration biopsy. Acta Radiol Diag 1976;17:813-28. 